\title{
Gastric B-cell mucosa associated lymphoid tissue lymphoma: a clinicopathological study in 56 patients
}

\author{
J M Castrillo, C Montalban, G Obeso, M A Piris, M C Rivas
}

\begin{abstract}
Clinico-pathological features of 56 patients with primary gastric lymphoma were evaluated retrospectively. All cases were regraded according to a classification of Isaacson $e t$ al into high grade and low grade B-cell mucosa associated lymphoid tissue lymphoma. A third group of mixed grade was recognised in 11 patients with low grade who also had occasional areas of high grade. Low grade and mixed grade patients had a $100 \%$ actuarial survival at 156 months, which was significantly better $(p<0.01)$ than that of $52 \%$ for patients with high grade disease. Different treatment methods surgery, chemotherapy, or a combination of both - did not significantly affect survival. Low grade tumours occurred mainly in men with a history of several years, and who presented with non-specific gastric symptoms without remarkable exploratory or laboratory findings: most patients were in stage IE-IIE and achieved remission and cure. High grade can have a shorter history, systemic symptoms, abnormal exploratory and laboratory findings, gastric tumour masses, stage IV disease, and a worse outcome. The only significant .prognostic factors for survival were the type of lymphoma and stage IV disease. These findings support the Isaacson classification system which separates two extreme groups of gastric lymphomas with different morphology, behaviour, and outcome. The presence of limited areas of high grade in a specimen showing low grade does not change the outcome but suggests that primary gastric lymphoma forms a continuum between these extreme types.

(Gut 1992; 33: 1307-1311)
\end{abstract}

Departments of Internal Medicine and Pathology, Fundacion Jimenez Diaz, Universidad Autonoma, Madrid

J M Castrillo

G Obeso

M C Rivas

Department of Internal Medicine, Hospital Ramon y Cajal, Universidad de Alcala, Madrid

C Montalban

Department of Pathology, Hospital Virgen de la Salud, Toledo, Spain M A Piris

Correspondence to: Dr M C Rivas, Department of Pathology, Fundacion Jimenez Diaz, Av Reyes Catolicos 2, Madrid 28040 Spain.

Accepted for publication 2 March 1992
Gastrointestinal lymphoma is uncomm but gastric lymphoma is the most frequent form ${ }^{13-17}$ and could be a good model for the evaluation of MALT tumour behaviour. ${ }^{13}$ Thus, the aim of this study was to evaluate retrospectively the characteristics and outcome of 56 cases of primary gastric lymphoma that have been morphologically reclassified according to recent knowledge of the MALT derived lymphomas.

\section{Methods}

In this series, 56 patients with primary gastric lymphoma were evaluated retrospectively. Only patients who fulfilled the criteria described by Isaacson $e t a l^{213}$ were included. Patients with secondary involvement of the stomach by nonHodgkin's lymphoma were therefore excluded. Thirty four patients were studied at the Fundacion Jimenez Diaz (Madrid), 14 at the Hospital Virgen de la Salud (Toledo) and eight at Hospital Ramon y Cajal (Madrid) between 1963 and 1990. Clinical data were obtained from their medical histories. Upper gastrointestinal radiography was performed in 42 patients and endoscopy with biopsy specimens in 48 patients. Laparotomy was performed for diagnosis or treatment, or both, in 50 cases. Five of the six patients who had not undergone operation were staged by computed tomography and bone marrow biopsy. Patients were staged according to the Ann Arbor system..$^{18}$ All specimens from gastrectomy, endoscopy, and bone marrow were routinely processed. A panel of monoclonal antibodies was used to characterise the gastric lymphoma in all 50 patients who had undergone surgery. All the cases were classified as B-cell lymphomas with a complete immunophenotype. ${ }^{19}$ All endoscopic biopsy specimens and gastrectomy materials were reviewed and classified according to the proposals of Isaacson et al.$^{20}$ A new group, mixed grade B-cell ${ }^{16} 192021$ was also included, when an otherwise typical low grade B-cell MALT lymphoma showed focal areas of high grade B-cell MALT lymphoma.

Gastric surgery was the only treatment in 10 patients with low grade, in three patients with mixed grade, and in nine patients with high grade lymphomas. Adjuvant chemotherapy with CHOP or CHOP-variants was used in three patients with low grade, in four patients with mixed grade, and in 10 patients with high grade disease. Two patients with low grade, two with mixed grade, and two with high grade were treated exclusively with chemotherapy. Two patients refused treatment. A complete remission was defined as the resolution of clinical, radiological, and endoscopic evidence of disease. A partial remission was considered as a reduction in tumour mass of $50 \%$.

Survival curves of the three histological groups were analysed according to the Kaplan and Meier method ${ }^{22}$ and the differences between these curves were calculated with the Mantle test. Analysis of survival was calculated in only 15 of the 20 patients in the low grade group, in 9 of 11 in the mixed grade group, and in 21 of 25 
with high grade lymphomas as 11 patients had either inadequate follow up or no treatment. The same methods were also used for the analysis of survival in patients treated with surgery, surgery plus chemotherapy, or chemotherapy alone.

Statistical comparisons of means or percentages were performed between sexes, ages, duration of symptoms before diagnosis, symptoms, data obtained from physical examination, laboratory data abnormalities, radiological and endoscopic findings, and the macroscopic appearances in the gastrectomy specimen in the joint low/mixed grade group $v$ those in the high grade group. In patients who had undergone operation a $\chi^{2}$ test was performed for the analysis of the possible association with mortality of the following variables: stage I-II $v$ stage IV disease, histological subtype low/mixed grade or high grade, presence or absence of gastric serosal invasion, presence or absence of lymphoma in the margin of resection or contiguous extension of the lymphoma to nearby abdominal organs, or both, and tumour size over or under $10 \mathrm{~cm}$. In the high grade group, a Cox's multivariate analysis $^{23}$ was performed to identify which of the following variables such as age, extension to adjacent organs or serosal invasion, stage, and mode of treatment (surgery, chemotherapy, or the combination of both) might be of independent significance in predicting mortality.

\section{Results}

The general characteristics of the patients are shown in Table I. Twenty were classified as low grade, 11 as mixed grade, and 25 as high grade.

TABLE I Primary gastric lymphoma-clinical and laboratory findings

\begin{tabular}{|c|c|c|c|}
\hline & $\begin{array}{l}\text { Low/mixed } \\
\text { grade }\end{array}$ & High grade & $p$ \\
\hline $\begin{array}{l}\text { No of patients } \\
\text { Sex: male/female } \\
\text { Mean (SD) age (years) (range) } \\
\text { Mean (SD) duration of symptoms (months) (range) }\end{array}$ & $\begin{array}{l}20 / 11 \\
21 / 10=2 \cdot 1 \\
58(13)(24-75) \\
30(73)(0 \cdot 2-360)\end{array}$ & $\begin{array}{l}25 \\
11 / 14=0 \cdot 78 \\
58(15)(23-79) \\
7(9)(0 \cdot 2-36)\end{array}$ & $p=0.08$ \\
\hline \multirow{27}{*}{$\begin{array}{l}\text { Symptoms (no }(\%)): \\
\text { Epigastric pain } \\
\text { Nausea and vomiting } \\
\text { Gastric bleeding } \\
\text { Dyspepsia } \\
\text { Weight loss } \\
\text { Anorexia } \\
\text { Malaise } \\
\text { Physical examination (no }(\%)): \\
\text { Palpable mass } \\
\text { Peripheral lymphadenopathy } \\
\text { Hepatomegaly } \\
\text { Splenomegaly } \\
\text { Hyponutrition } \\
\text { Tenderness } \\
\text { Ascites } \\
\text { Pleural effusion } \\
\text { Normal } \\
\text { Laboratory abnormalities }(\text { no }(\%)): \\
\text { Anaemia }(\text { Hb }<10 \text { g/dl) } \\
\text { ESR over } 40 \text { mm } \\
\text { Serum LDH level }>500 \mathrm{U} / 1 \\
\text { Alkaline phophatase }>280 \mathrm{U} / \mathrm{l} \\
\text { Monoclonal globulin } \\
\text { Raised ALT levels } \\
\text { Low protein level } \\
\text { Normal }\end{array}$} & & & \\
\hline & $24(77)$ & $18(72)$ & \multirow{3}{*}{$\mathrm{p}<0.01$} \\
\hline & $15(48)$ & $3(12)$ & \\
\hline & $12(38)$ & $9(36)$ & \\
\hline & $13(41)$ & $10(40)$ & \multirow{4}{*}{$\begin{array}{l}\mathrm{p}<0.05 \\
\mathrm{p}<0.0002\end{array}$} \\
\hline & $11(35)$ & $18(72)$ & \\
\hline & $7(22)$ & $19(76)$ & \\
\hline & $7(22)$ & $12(48)$ & \\
\hline & & & \multirow{10}{*}{$\mathrm{p}<0.05$} \\
\hline & $2(6)$ & $8(32)$ & \\
\hline & $2(6)$ & $5(20)$ & \\
\hline & $2(6)$ & $6(24)$ & \\
\hline & & $1(4)$ & \\
\hline & $1(3)$ & $4(16)$ & \\
\hline & $9(29)$ & $2(8)$ & \\
\hline & $1(3)$ & & \\
\hline & $1(3)$ & & \\
\hline & $15(48)$ & $7(28)$ & \\
\hline & & & \\
\hline & $3(9)$ & $4(16)$ & \\
\hline & $8(25)$ & $12(48)$ & \\
\hline & $2(6)$ & $7(28)$ & \\
\hline & $6(19)$ & $6(24)$ & \\
\hline & $4(13)$ & $1(4)$ & \\
\hline & $6(19)$ & $6(24)$ & \\
\hline & $10(32)$ & $1(4)$ & $\mathrm{p}<0.05$ \\
\hline & Low grade & Mixed grade & High grade \\
\hline \multicolumn{4}{|l|}{ Pathological stage $(\%)^{\star}$} \\
\hline IE & $16 / 20(80)^{\star \star}$ & $6 / 10(60)$ & $9 / 25(36)$ \\
\hline IIE & $4 / 20(20)$ & $3 / 10(30)$ & $11 / 25(44)$ \\
\hline IV & $0 / 20$ & $1 / 10(10)$ & $5 / 25(20)$ \\
\hline
\end{tabular}

$\star 6$ patients not laparotomised. Clinical stage only (1 low grade, 3 mixed grade, 2 high grade).

$\star \star 1$ patient was not staged.
Men outnumbered women in the low/mixed grade group by a ratio of $2 \cdot 1$. This ratio was 0.78 in the high grade group. In the low/mixed grade group the mean age was 58 (13) years (range 24 to 75 ) and in the high grade group it was 58 (15) years (range 23 to 79). Seventy four per cent of patients were over 51 years old. The mean duration of symptoms before diagnosis was $30(73)$ months in the first group and $7(9 \cdot 5)$ in the second $(p=0 \cdot 08)$. In both groups the presenting symptoms that required hospital consultation were mostly ulcer related pain and a change in longstanding chronic symptoms. Main symptoms at diagnosis were abdominal pain $77 \%$ in the low/mixed grade group and $72 \%$ in the high grade group), dyspepsia ( $41 \%$ in the low/mixed grade and $40 \%$ in the high grade group), and upper gastrointestinal bleeding (38\% and $36 \%$ respectively). Patients in the low/mixed grade group referred to frequent vomiting $(48 \%)$ and patients in the high grade group had weight loss $(72 \%)$, anorexia $(76 \%)$, and general deterioration (48\%). In the physical examination of the low/ mixed grade group, abdominal tenderness was the only relatively common finding, occurring in $29 \%$, and in $48 \%$ physical examination disclosed no abnormality. In the high grade group, a palpable mass was found in $32 \%$, hepatomegaly in $24 \%$, undernourishment in $16 \%$, and peripheral lymphadenopathy in 20\%: no abnormality was found in $28 \%$ of these patients. Routine laboratory investigations were not significantly abnormal in the low/mixed grade group and were, in fact, completely normal in $32 \%$ of these patients. In the high grade group, $48 \%$ had raised erythrocyte sedimentation rates, $28 \%$ serum lactate dehydrogenase values over $500 \mathrm{U} / \mathrm{l}, 24 \%$ raised alkaline phosphatase activities, $24 \%$ low total protein concentrations, and $16 \%$ anaemia; only $4 \%$ of patients in this group had all determinations within normal ranges.

In the low grade group, 16 of $20(80 \%)$ patients were staged as IE and 4 of $20(20 \%)$ as IIE. In the mixed grade group 6 of $10(60 \%)$ were staged as IE, 3 of $10(30 \%)$ as IIE, and another case as IV. One case was not clearly staged. In the high grade group 9 of 25 (36\%) patients were stage IE, 11 of $25(44 \%)$ stage IIE, and 5 of $25(20 \%)$ were stage IV.

Radiological, endoscopic, and macroscopic findings in the gastrectomy specimens are shown in Table II. The macroscopic pattern found in surgical specimens correlated with the radiological pattern in only 7 of $18(38 \%)$ of the low/ mixed grade group and in 5 of $16(31 \%)$ of the patients in the high grade group; the patterns correlated with the endoscopic findings in only 8 of $19(42 \%)$ of the low/mixed grade group and in 7 of $17(41 \%)$ of the high grade group. In the gastrectomy specimen an infiltrative/ulcerative pattern was found in a significant percentage of cases with low/mixed grade lymphoma $(\mathrm{p}<0.05)$ and a large tumour mass in patients with high grade $(\mathrm{p}<0.01)$.

In the low grade group, all 15 patients achieved complete remission and in the mixed grade group $8(88 \cdot 8 \%)$ patients achieved complete and $1(11 \%)$ partial remission. In the high grade group, complete remission was achieved in 
TABLE II Primary gastric lymphomas - upper gastrointestinal radiology, endoscopy, and gastrectomy specimen patterns. (Values, no (\%))

\begin{tabular}{|c|c|c|c|c|c|c|}
\hline \multirow[b]{2}{*}{ Pattern } & \multicolumn{2}{|l|}{ Radiology } & \multicolumn{2}{|c|}{ Endoscopy } & \multicolumn{2}{|c|}{ Gastrectomy } \\
\hline & $\begin{array}{l}L G / M G \\
(n=23)\end{array}$ & $\begin{array}{l}H G \\
(n=19)\end{array}$ & $\begin{array}{l}L G / M G \\
(n=27)\end{array}$ & $\begin{array}{l}H G \\
(n=21)\end{array}$ & $\begin{array}{l}L G / M G \\
(n=27)\end{array}$ & $\begin{array}{l}H G \\
(n=23)\end{array}$ \\
\hline Infiltrative/ulcers & $9(39)$ & $10(52)$ & $10(37)$ & $9(42)$ & $12(44)$ & $.05^{1(4)}$ \\
\hline $\begin{array}{l}\text { Infiltrative/erosions } \\
\text { Infiltrative } \\
\text { Ulcers } \\
\text { Tumour/mass }\end{array}$ & $\begin{array}{l}\overline{9}(39) \\
5(22) \\
-\end{array}$ & $\begin{array}{l}\overline{3}(16) \\
3(16) \\
3(16)\end{array}$ & $\begin{array}{c}5(27) \\
\overline{12}(44) \\
-\end{array}$ & $\begin{array}{l}2(9) \\
\overline{8}(38) \\
2(9)\end{array}$ & $\begin{array}{l}4(15) \\
\overline{7}(26) \\
4(15)\end{array}$ & $\begin{array}{l}- \\
\overline{-} \\
\overline{2}(96)\end{array}$ \\
\hline
\end{tabular}

$\mathrm{LG} / \mathrm{MG}=$ low/mixed grade; $\mathrm{HG}=$ high grade .

12 patients (57\%), partial remission in $3(14 \%)$, and there was no response in $6(28 \%)$. The mean duration of complete remission in the low grade group was 65 (48) months (range 6 to 156) and only 1 of $15(6.6 \%)$ patients relapsed after 48 months. In the mixed grade group, the mean duration of complete remission was 46 (31) months (range 5 to 88) and no relapse was recorded. In the high grade group, the mean duration of complete remission was 66 (101) months (range $4-354) ; 2$ of $12(16 \cdot 7 \%)$ of the patients in complete remission relapsed after 48 months.

Actuarial survival in the low and mixed grade groups was $100 \%$ at 156 months, significantly better $(p<0.01)$ than the $52 \%$ survival in the high grade group (Figure). Only two patients with low grade or mixed grade disease died, but in neither case was the cause related to lymphoma. However, nine patients in the high grade group died. Six of these died between 10 to 60 days after surgery. All these patients had bulky gastric tumours extending to nearby or distant organs and death was due to progressive and uncontrollable disease and was not directly related to surgery. The two patients who had a late relapse died, and in another patient death was not related to lymphoma. In the whole series, actuarial survival was not significantly different in patients treated with surgery, surgery plus chemotherapy, or chemotherapy alone. Higher grade of histological malignancy $(p<0.01)$ and stage IV disease $(p<0.05)$ were the only variables that influenced mortality. In the high grade group, none of the variables or different modes of treatment influenced mortality.

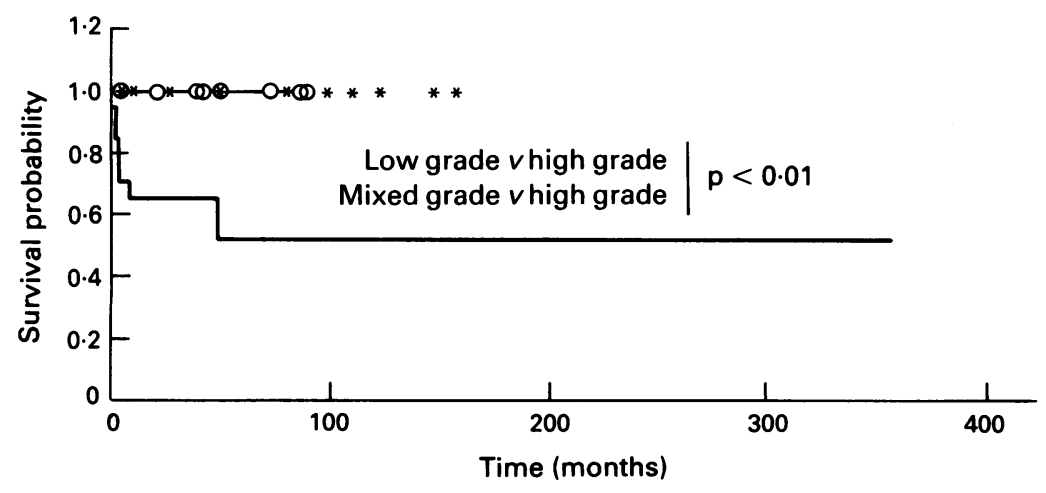

\begin{tabular}{|c|c|c|}
\hline - High grade & $\begin{array}{l}\text { Mixed grade } \\
(n=9)\end{array}$ & $\begin{array}{l}* \text { Low grade } \\
(n=15)\end{array}$ \\
\hline
\end{tabular}

Survival probability in the three groups of patients with primary gastric lymphomas. Mixed grade=low grade with occasional areas of high grade.
In four patients, a second neoplasm was associated with the gastric lymphoma - one had coexisting gastric carcinoma, another a coexisting colonic carcinoma, and a third developed urothelial carcinoma 11 years after treatment with a chemotherapeutic regimen that included cyclophosphamide. A gastric lymphoma developed in the fourth patient seven years after radiotherapy treatment for Hodgkin's disease.

\section{Discussion}

In most series patients with primary gastric lymphoma have been classified according to Rappaport, ${ }^{2+27}$ Kiel, ${ }^{101+1528}$ Lukes-Collins, ${ }^{1029}$ or Working Formulation systems..$^{102252930}$ These classifications are able to separate groups of nodal lymphomas with a clear correlation between morphological features and clinical behaviour. However, these classifications cannot successfully be extrapolated to gastrointestinal lymphomas as MALT lymphocytes and their derived lymphomas seem to have a physiology that differs from their nodal counterparts. ${ }^{27}$ In this study, cases have been classified according to the system proposed by Isaacson et $a l^{20}$ in an attempt to evaluate its reliability in separating different types of gastric lymphoma. Cases were classified into two groups of MALT lymphomas: low grade and high grade with or without a low grade component. ${ }^{20}$ However, in a previous report, using morphological, microscopic and ultrastructural criteria, and immunological markers, we found that $46 \%$ of the patients with low grade malignancy had areas with a population of large cells reflecting the presence of a high grade malignant component. ${ }^{21}$ Thus, we have also included a third group, the mixed grade MALT lymphoma already discussed 16192021 but not included in the initial classification of Isaacson et al.$^{20}$ In this series, 11 cases have been classified as mixed grade, representing a considerable percentage of all cases of B-cell MALT lymphoma (19.6\%). This finding suggests that primary gastric MALT lymphoma forms a continuum with well delineated entities at either end, which have a graded sequence of an increasing amount of large cells. It is also possible that in this continuum a tumour increases the amount of large cells and develops higher grades of malignancy transforming low grade into high grade as occurs in nodal counterparts.

Actuarial survival in both low grade and mixed grade is excellent, with a $100 \%$ probability of survival after 156 months of treatment. This survival is significantly better $(p<0.01)$ than that of the patients with high grade lymphoma whose probability of survival is limited to $52 \%$. This different outcome confirms that the grouping proposed by the Isaacson classification ${ }^{716^{20}}$ is reliable in terms of prognosis and that the presence of a limited component of high grade in a low grade case has no ominous prognostic significance.

In the whole series there were no differences in survival in the groups treated with chemotherapy, surgery, or the combination of both. These results and the good overall survival of the low grade and mixed grade groups underline the facts that most of these patients had localised 
disease, that after achieving complete remission most patients are cured, ${ }^{915}$ and that surgery can be a definitive treatment. ${ }^{2+2829}$ However, in the high grade group the disease can present with a bulky gastric tumour extending to nearby or distant organs and can display much more aggressive behaviour which cannot be controlled by surgery. This presentation implies a very poor prognosis despite treatment, as was the case in six patients in this series. Relapses in high grade patients also seem to be ominous events as both patients who relapsed have died. Patients who did not present with bulky or extensive initial disease and who did not relapse after complete remission had a good prognosis, comparable with that of low or mixed grade patients.

In the high grade group in this series, surgery, chemotherapy, or the combination of both, did not influence survival and the effectiveness of the different modes of treatment needs further assessment. Some authors maintain that effective gastrectomy is essential for cure, ${ }^{10142429}$ while others suggest that surgery alone is insufficient and a combination of chemotherapy and surgery is better. ${ }^{25}{ }^{31}$ Others have shown that surgery does not improve the results of chemotherapy or radiotherapy. ${ }^{262830}$ Moreover, only two thirds of tumours are resectable at surgery. ${ }^{1026}$ Gastrectomy is not devoid of complications, mortality has been reported as being as high as $16 \%{ }^{142}$ and there is a high incidence of short and long term complications after surgery. ${ }^{25} 28$ The use of endoscopic biopsy specimens in histopathological diagnosis ${ }^{26} 27$ and of imaging techniques in staging disease extent avoids the need for laparotomy and gastrectomy which consequently can be reserved for a minority of cases..$^{2728}$ A recent prospective study of high grade gastric lymphoma ${ }^{30}$ found that survival was similar in patients who underwent complete, incomplete, or no surgical therapy before chemotherapy and that the prognostic factors predicting survival were similar to those in patients with nodal lymphoma treated with the same chemotherapy regimen. This finding supports the view that chemotherapy should be the elective treatment in this group. Although bleeding and perforation have been feared complications in non-operated patients they have not occurred in this series or in others..$^{2732}$ If these results can be confirmed, chemotherapy without gastrectomy should be the treatment of choice for aggressive gastric lymphomas.

When the characteristics and the extent of the gastric MALT lymphoma are considered, only the histological grade and stage IV disease (as in all major series ${ }^{152433}$ ) influenced mortality. Tumour size over $10 \mathrm{~cm}$, presence of disease in the margins of resection, or extension to adjacent organs had no influence. Neither the classical variables nor the different treatments influenced survival in high grade lymphoma. These data support the validity of classifying the two different grades of gastric MALT lymphoma. ${ }^{20}$

Clinical findings also support the view that low and mixed grade form a specific group that can be separated from the high grade group. In both groups, patients were middle aged to elderly, but there is a striking incidence of low/mixed grade in men that is not found in the high grade group. Although in both groups the disease can be either indolent or slowly progressive and most cases had a non-aggressive course, in patients grouped as low/mixed grade the disease can last for years and in those grouped as high grade for months only, a difference that is almost significant. The symptoms are non-specific and not very different in either group, except for the incidence of anorexia, weight loss, and a general malaise in high grade patients. Reflecting this scarcity of symptoms, physical examination is normal in almost $50 \%$ of patients with low/mixed grade and in $28 \%$ of those with high grade. In the high grade group it is common to find a palpable mass, hepatomegaly or splenomegaly, and palpable lymphadenopathy. Anaemia, raised erythrocyte sedimentation rates, and serum lactate dehydrogenase activities are common findings in high grade, but the analytical findings are normal in up to one third of the patients with low/mixed grade. Although both groups tend to appear as a limited disease, most cases being in stage I-IIE, the morphohistological subtype seems to be a decisive factor in dissemination, as only one case (5\%) of low/mixed grade compared with $20 \%$ of the patients with high grade were classified as stage IV. Upper gastrointestinal radiography and endoscopy are very sensitive in showing the presence of gastric disease, with infiltrative and and ulcerative patterns in both groups and a tumour pattern only in high grade. These procedures can detect the disease, but they are not so accurate as the macroscopic study of a surgical specimen in determining the pattern and extension of the tumour. The correlations between radiology and endoscopy and the surgical specimen were very poor: there was agreement with the surgical specimen in only 31 to $38 \%$ and in 41 to $42 \%$ respectively.

A final point is the occurrence of nonlymphoid neoplasias in four patients. This association means that primary gastric MALT lymphoma can develop as a second neoplasm or that other neoplasms can occur in both treated and untreated patients with gastric lymphoma. Despite the slow non-aggressive course of gastric lymphoma, these patients behave as immunocompromised subjects who may eventually develop immunodeficiency-related secondary neoplasias. Moreover, a high incidence of gastric adenocarcinomas coexisting (over 60 cases) or following (17 cases) gastric lymphomas have been reported. ${ }^{34}$ This increased incidence of gastric carcinomas seems to be related to local factors. An increased proliferative capacity of the gastric epithelium next to the areas of MALT derived lymphomas has been postulated (P G Isaacson, personal communication) as a possible mechanism. Helicobacter pylori infection is associated with an increased risk of gastric adenocarcinoma ${ }^{3536}$ and is also found in $92 \%$ of patients with gastric MALT lymphoma, ${ }^{37}$ supporting its role as cofactor in the pathogenesis of both diseases. This finding may explain the eventual synchronous or metachronous occurrence of these two diseases in the same patient.

In summary, the two types low/mixed grade and high grade recognised in the Isaacson classification $^{20}$ delineate two extreme types of gastric 
MALT lymphomas that differ in their presentation, clinical behaviour, and response to treatment. ${ }^{13}$ Low/mixed grade occur in elderly men with a history extending over several years, nonspecific local symptoms, no abnormal exploratory or laboratory findings, a gastric infiltrative/ ulcerative pattern, limited stage I-II disease, and with a very good response to treatment and prolonged survival. On the other hand, although high grade may follow a similar course, in some patients it is associated with systemic symptoms, laboratory and exploratory abnormalities, large tumour masses in the stomach, extensive and disseminated disease, and failure of treatment leading to a poor prognosis.

We are indebted to Professor P G Isaacson for his critical review of the manuscript and Dr J Muñiz and Dr R Gabriel for their advice in the statistical study.

1 Freeman C, Berg JW, Cutler SJ. Occurrence and prognosis of extranodal lymphomas. Cancer 1972; 29: 252-60.

2 Isaacson PG, Wright DH. Extranodal lymphoma. In: Anthony P, Mac Sween RNM, eds. Recent advances in histopathology. London: Churchill-Livingstone, 1987: 159-84.

3 Spencer J, Finn T, Isaacson PG. Human gut-associated lymphoid tissue: a morphological and immunocytochemical study of the human appendix. Gut 1985; 26: 672-9.

4 Spencer J, Finn T, Isaacson PG. A comparative study of the gut-associated lymphoid tissue of primates and rodents. Virchow Arch [B] (cell Pathol) 1986; 51: 509-19.

5 Bienenstock J, Befus D. Gut and bronchus associated lymphoid tissue. Am $\mathcal{F}$ Anat 1984; 170: 437-45.

6 Isaacson PG, Wright DH. Malignant lymphoma of mucosaassociated lymphoid tissue. A distinctive type of B-cell lymphoma. Cancer 1983; 52: 1410-6.

7 Isaacson PG, Spencer J. Malignant lymphoma of mucosaassociated lymphoid tissue. Histopathology 1987; 11: 445-62.

8 Lewin K, Ranchod M, Dorfman RF. Lymphomas of the gastrointestinal tract. Cancer 1978; 42: 693-707.

9 Filippa DA, Lieberman PH, Weingrad DN, Decosse JJ, Bretsky SS. Primary lymphomas of the gastrointestinal tract. Analysis of prognostic factors with emphasis on histological type. Am 7 Surg Pathol 1983; 7: 363-72

10 Dragosic B, Bauer P, Radaszkiewiczt T. Primary gastrointestinal non-Hodgkin's lymphomas. A retrospective study of 150 cases. Cancer 1985; 55: 1060-73.

11 Papadimitriou CS, Papacharalampous NX, Kittas C. Primary gastrointestinal malignant lymphoma. Cancer 1985; 55: 870-9.

12 Burke JS, Sheibani K, Nathwani BN, Winberg CD, Rappaport H. Monoclonal small (well-differentiated) lymphocytic proliferation of the gastrointestinal tract resembling lymphoid hyperplasia. Hum Pathol 1987; 18: resembling

13 Isaacson PG, Spencer J, Finn T. Primary B-cell gastric lymphoma. Hum Pathol 1986; 17: 72-82.

14 Hockey MS, Powell J, Crocker J, Fielding JW. Primary gastric lymphoma. Br f Surg 1987; 74: 483-7.

15 Ravaioli A, Amadori M, Faedi M, Rosti G, Folli S, Barbieri C, et al. Primary gastric lymphoma: a review of 45 cases. Eur $\mathcal{F}$ Cancer Clin Oncol 1986; 22: 1461-5.

16 Moore I, Wright DH. Primary gastric lymphoma. A tumour of mucosa-associated lymphoid tissue. A histological and immunohistochemical study of 36 cases. Histopathology 1984; 8: 1025-39.
17 Barzilay J, Rakowsky E. Gastric lymphoma: a clinical study of 28 cases and evaluation of prognostic factors. Clin Oncol $1984 ; 10: 233-40$.

18 Carbone PP, Kaplan HS, Musshoff K, Smithers DW, Tubiana M. Report of the Committee on Hodgkin's disease staging procedures. Cancer Res 1971; 31: 1860-1.

19 Piris MA. Linfomas gástricos B del tejido linfoide asociado a mucosas (MALT). Estudio humano y experimental. Conmucosas (MALT). Estudio humano y experimental. ConMadrid: Facultad de Medicina, Universidad Autonoma, Madrid: Facultad de

20 Isaacson PG, Spencer J, Wright DH. Classifying primary gut ymphomas. Lancet 1988; ii: 1148-9.

21 Piris MA, Rivas C, Morente M, Orradre JL, Rodriguez R, Cruz MA, et al. Gastric B-cell low grade lymphoma originated in mucosa-associated lymphoid tissue. Relationship of tumoral cells with marginal zone and monocytoid B-lymphocytes. Immunohistochemical and ultrastructura studies. Med Clin (Barc) 1990; 94: 601-6.

22 Kaplan EL, Meier P. Non parametric estimation from incomplete observations. F Am Stat Assoc 1958; 53: 457-81.

23 Cox DR. Regression models and life tables. F Stat Soc 1972; 34: 187-220.

24 Rosen CB, Van Heerden JA, Martin JK, Wold LE, Ilstrup $D M$. Is an aggressive surgical approach to the patient with gastric lymphoma warranted? Ann Surg 1987; $205:$

25 Shiu MH, Nisce LZ, Pinna A, Straus DJ, Tome M, Filippa DA, et al. Recent results of multimodal therapy of gastric lymphoma. Cancer 1986; 58: 1389-99.

26 Maor MH, Maddux B, Osborne BM, Fuller LM, Sullivan JA Nelson SR, et al. Stages IA and IIE non-Hodgkin's ymphomas of the stomach. Comparison of treatment modalities. Cancer 1984; 54: 2330-7.

27 Maor MH, Velasquez WS, Fuller LM, Silvermintz KB. Stomach conservation in stages IE and IIE gastric nonHodgkin's lymphoma. I Clin Oncol 1990; 8: 266-71.

28 Gobbi PG, Dionigi P, Barbieri F, Corbella F, Bertoloni D Grignani $\mathrm{G}$, et al. The role of surgery in the multimodal treatment of primary gastric non-Hodgkin's lymphomas. treatment of primary gast

29 List AF, Greer JP, Cousar JC, Stein RS, Johnson DH, Reynolds VH, et al. Non-Hodgkin's lymphoma of the gastrointestinal tract: an analysis of clinical and pathologica features affecting outcome. $7 \mathrm{Clin}$ Oncol 1988; 6: 1125-33.

30 Salles G, Herbrecht R, Tilly H, Berger F, Brousse N, Gisselbrecht C, et al. Aggressive primary gastrointestina lymphomas: review of 91 patients treated with the LNH-84 regimen. A study of the Groupe d'Etude des Lymphomes Agressifs. Am $\mathcal{F}$ Med 1991; 90: 77-84.

31 Burgers JM, Taal BG, Van Heerde P, Somers R, den Hartog Jager FC, Hart AA. Treatment results of primary stage I and Jager FC, Hart AA. Treatment results of primary stage $I$ and Oncol 1989; 11: 319-26.

32 Hermann R, Panahon A, Barcos MP, Walsh D, Stuztman L. Gastrointestinal involvement in non-Hodgkin's lymphoma. Cancer 1980; 46: 215-22.

33 Aozasa K, Ueda T, Kurata A, Kim CW, Inoue M, Matsuura N, et al. Prognostic value of histologic and clinical factors in 56 patients with gastrointestinal lymphomas. Cancer 1988; 61: 309-15.

34 Garcia-Giron C, Feliu J, Ordoñez A, Zamora P, Blanco S, Sanchez MJ, et al. Gastric adenocarcinoma after treatment of gastric non-Hodgkin's lymphoma. Med Clin (Barc) 1990; g5: 698-701.

35 Parsonnet J, Friedman GD, Vandersteen DP, Chang Y, Vogelman JH, Orentreich N, et al. Helicobacter pylori Vogelman JH, Orentreich $\mathrm{N}$, et al. Helicobacter pylori infection and the risk

36 Nomura A, Stemmermann GN, Chyou PH, Kato I, PerezPerez G, Blaser MJ. Helicobacter pylori infection and gastric carcinoma among Japanese Americans in Hawaii. $N$ Engl f Med 1991; 325: 1132-6.

37 Wotherspoon AC, Ortiz-Hidalgo C, Falzon MR, Isaacson PG. Helicobacter pylori associated gastritis and primary B-cell gastric lymphoma. Lancet 1991; 338: 1175-6. 